\title{
THE KNOWLEDGE-BASED ECONOMY IN LITHUANIA: ANALYSIS OF TENDENCIES
}

\author{
Romualdas Ginevičius ${ }^{1}$, Renata Korsakienè ${ }^{2}$ \\ Vilnius Gediminas Technical University, Saulètekio al. 11, 10223 Vilnius-40, Lithuania \\ E-mail: romualdas.ginevicius@adm.vtu.lt'; renatakorsa@takas.lt ${ }^{2}$
}

Received 1609 2005; accepted 14112005

\begin{abstract}
The purpose of this paper is to analyse the tendencies of knowledge-based economy in Lithuania by looking at a knowledge economy's major dimensions - the structure of economic activity and the infrastructure of knowledge economy. The knowledge-based economy is the dominant post-industrial economic development paradigm. The emergence of this paradigm in the 1980s created preconditions to emphasize the role of knowledge creation and distribution as the primary driver in the process of economic development and growth, the distribution of income, development of knowledgebased networks among firms and the interface between government, business and citizens in the advanced economies.
\end{abstract}

Keywords: The knowledge-based economy, Lithuanian economy, infrastructure of knowledge economy.

\section{Introduction}

The term "knowledge-based economy" is used to characterize the economy in which knowledge plays a crucial role and the generation of knowledge is the main precondition of growth. Scholars point out that new information and communication technologies as well as increasing globalization allow "knowledge economies" to focus upon knowledge intensive activities, the production, processing and transfer of knowledge (Barnacle, 2004). In global economy the competitive advantage lie increasingly in such local things as knowledge, relationships, and motivation" (Porter, 1998). Thus, the ability of Society to acquire and use knowledge is a key factor in determining the competitiveness of a country economy. On the other hand if a country is lacking in resources, creativity helps to find ways for their effective use or substitute and in such way reduces shortages.

Lithuania as well as other post-communist countries has covered a complicated way of reform from planned to market economy. Reforms that were performed in all spheres of life created preconditions to eliminate many obstacles and crises enabled
Lithuania to substantially change its juridical base, to implement solutions, which laid the foundations for a market to work. In 2000 the European Commission Report stated, that Lithuania can be regarded as a functioning market economy and should be able to cope with competitive pressures and market forces within the Union in the medium term. It had to be noted that the EU has set a task to create a knowledge society in the nearest decade; Lithuania could reach a similar level in this field in 2015.

In recent years Lithuania has made progress in a few areas of the knowledge-based economy, particularly in terms of improving the economic and institutional regime and developing infrastructure for information and communications technology (World Bank, 2003). But less progress has been made on improving education systems, and Lithuania has performed poorly in advancing its systems for innovation.

The paper analyses the tendencies of knowledge-based economy in Lithuania by looking at a knowledge economy's major dimensions - the structure of economic activity and the infrastructure of knowledge economy. 


\section{Literature Review}

Following the definition proposed by the OECD knowledge economies are "those which are directly based on the production, distribution and use of knowledge and information" (OECD, 1996). The early scientific discussions regarding the nature of knowledge have been developed by Arrow, who emphasized "learning by doing" and Rosenberg, who stressed the idea of "learning by using" (Arrow, 1962), Rosenberg, 1982). Further scientific works have developed the importance of tacit knowledge (Howells, 1996). Hence, in the transition process from industrial to the post industrial society the knowledge is replacing capital.

The shift toward knowledge-based economy put emphasis on high skill industries that are capable to generate innovations. Hence, research and development activities are to be seen as one of the key factors in the process of innovation creation. On the other hand, the knowledge based economy creates the prerequisites to generate the demand for workers who are highly skilled and well educated (Sporer, 2004). Therefore it is not accidental that the education plays one of the leading roles in the transition toward knowledge based economy. National governments are restricted to manage their domestic economies. However, as state some authors: "education remains one area of central significance to economic growth and prosperity, which they are still able to influence" (Roberts, 2001). Scholars point out that relationship between universities, research and development, and business is to be seen as a balance between science push and market pull factors (Muller \& Etzkowitz, 2000).

Notably that shift toward knowledge-based economy is driven by two principal processes. Sporer point out that contextual change for the operation of modern societies and economies, commonly called globalization is to be seen as a driving force (Sporer, 2004). On the other hand, new information and communication technologies foster the full utilization of the innovations.

\section{Overview of Lithuanian economy}

Lithuania has started to participate in the knowledge economy. For instance, Lithuania has participated in EU research programs, prepared a white paper on science and technology, adopted various information society and e-government strategies, and signed a memorandum of understanding on information society development between the private sector and the
Government. However, the analysis of statistical data allows concluding that other countries move ahead Lithuania in persuading knowledge economy.

It should be noted that the structure of economy is to be perceived as significant determinant of development of the knowledge economy of any country. The scholars state that "an economy whose comparative advantage is new knowledge requires a very different industrial structure as well as economic values" (Audretsch \& Thurik, 2000).

Analysis of further trends shows that amongst OECD countries there has been a shift in the structure of value added and trade with the declining share of low and medium-low technology industries and the increasing share of high technology industries. For instance during the 1990s the share of medium-high and high technology industries in international trade increased from 18 to $25 \%$ (OECD, 1999). However, Lithuania is dominated by low-skill industries (50.6 percent) and medium-skill/white-collar (36.7 percent) industries, with the low share of medium-skill/bluecollar (9.2 percent) and moderate share of the highskill industry ( 3.5 percent) (European Trend Chart on Innovation, 2003-2004). Hence, from the presented data, we can draw a conclusion that despite the high share of low-skill industries, the medium skill/white collar industries are very important within the Lithuanian industrial structure. Anyway, in comparison with OECD countries, where the fastest growing industries are pharmaceuticals, radio, TV and communications equipment and computers, Lithuania is dominated by low-tech industries (73 percent of total) with moderate shares of high - tech (4.4 percent), mid - high tech (12.8 percent), and mid-low tech $(9.8$ percent) industries.

The issue seems to be even more urgent, when the share of Research \& Development as a percentage of GDP is considered. It should be noted that the Lithuanian economy has grown steadily during the last years (in 2003, Lithuania's GDP grew by $8.9 \%$ ). However, when the Research \& Development (R\&D) expenditures as a percentage of GDP of Lithuania were compared, it was established that it was one of the smallest among the EU-25 (Statistics in Focus, 2005). Sweden and Finland are ahead of all countries with respectively $4.27 \%$ and $3.51 \%$ of R\&D intensity. Meanwhile, Lithuania's expenditure reaches only $0.68 \%$ and is far away from the $3 \%$ level that was established by Lisbon strategy (Figure 1).

Anyway, close look at the percentage of the total gross domestic expenditure on $\mathrm{R} \& \mathrm{D}$ by foreign funds (Table 1) confirms, that, Lithuania is behind EU-25 level 


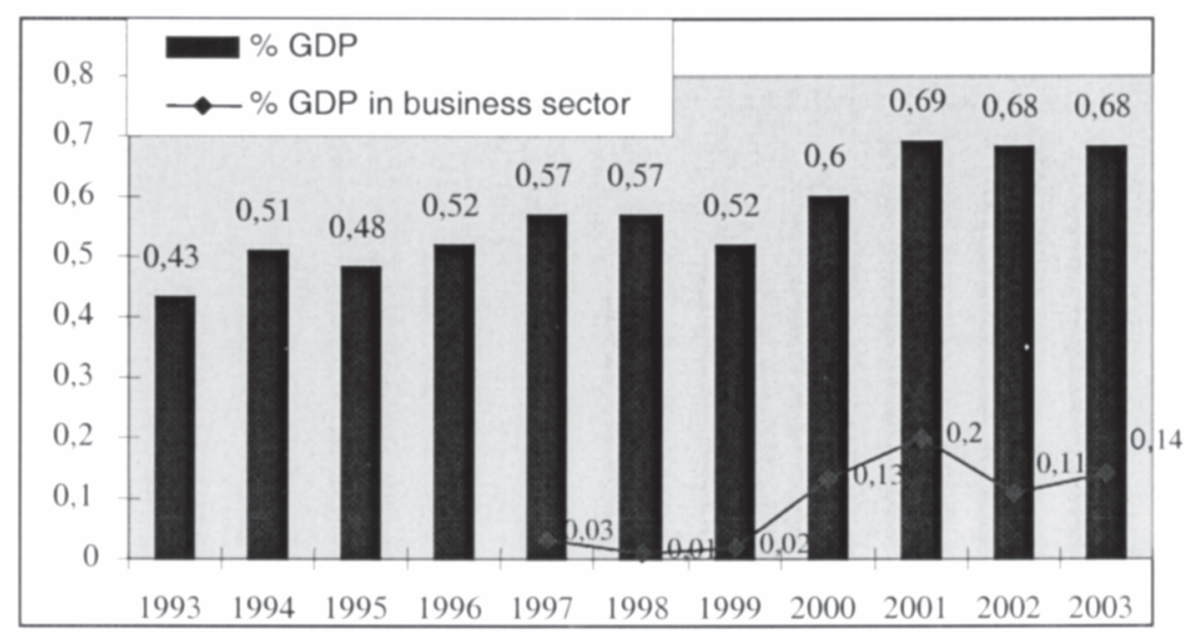

Figure 1. R\&D funding in Lithuania (Source: Department of Statistics of Lithuania)

( $8.2 \%)$. On the other hand Latvia and Estonia had higher percentage of R\&D financing from abroad with respectively $35.6 \%$ and $14.4 \%$ of expenditure (Statistics in Focus, 2005).

Another benchmark of knowledge economy is IT expenditure as a percentage of GDP. Examination of data provided in Table 2 (IT expenditure as \% of GDP) revealed that in 2003 Lithuania's IT expenditure was $1.9 \%$ of GDP and was among the lowest. The statistical data show that other Baltic Countries: Estonia and Latvia are ahead Lithuania with respectively $3.4 \%$ and $2.4 \%$ of IT expenditure as $\%$ of GDP.

Table 1. The percentage of the total gross domestic expenditure on R\&D (GERD) by foreign funds for years 1994 and 2002 (descending) (Source: Eurostat)

\begin{tabular}{|l|r|r|}
\hline \multicolumn{1}{|c|}{ Country } & \multicolumn{1}{c|}{$\mathbf{1 9 9 4}$} & $\mathbf{2 0 0 2}$ \\
\hline$E U-15$ & 6.5 & 8.3 \\
\hline$E U-25$ & $22.8(1995)$ & 8.2 \\
\hline Latvia & $8.0(1998)$ & 35.6 \\
\hline Cyprus & $6.2(1998)$ & 15.1 \\
\hline Estonia & 3.7 & 14.4 \\
\hline Hungary & $6.7(2000)$ & 10.4 \\
\hline Lithuania & 1.4 & 7.1 \\
\hline Poland & 2.6 & 4.8 \\
\hline Slovenia & $3.3(1995)$ & 3.7 \\
\hline Czech Republic & 1.3 & 2.7 \\
\hline Slovakia & & 2.1 \\
\hline & 0.6 & \\
\hline Romania & no data & 7.0 \\
\hline Bulgaria & 1.7 & 5.0 \\
\hline Croatia & & 1.5 \\
\hline Turkey & & 1.3 \\
\hline
\end{tabular}

It should be noted that there is a widely accepted notion that the country's transition to knowledge economy is closely linked with the increase of investment into appropriate sectors (Makarov, 2004). Hence, implications of the EU accession require undertaking active state policy aimed to increase expenditure into such areas as $R \& D$ and IT development.

Table 2. IT Expenditure as \% of GDP (Source: Eurostat)

\begin{tabular}{|l|r|r|r|r|}
\hline \multicolumn{1}{|c|}{ Country } & \multicolumn{1}{|c|}{$\mathbf{2 0 0 0}$} & \multicolumn{1}{c|}{$\mathbf{2 0 0 1}$} & \multicolumn{1}{c|}{$\mathbf{2 0 0 2}$} & \multicolumn{1}{c|}{$\mathbf{2 0 0 3}$} \\
\hline EU (15 ountries) & 3,3 & 3,2 & 3 & 3 \\
\hline Euro-zone & 3 & 2,9 & 2,7 & 2,7 \\
\hline Bulgaria & 1,9 & 1,9 & 1,9 & 2 \\
\hline Czech Republic & 3,3 & 3,4 & 3,7 & 3,8 \\
\hline Estonia & 3,7 & 3,5 & 3,5 & 3,4 \\
\hline Hungary & 3,2 & 3,1 & 2,9 & 2,9 \\
\hline Lithuania & 1,6 & 1,7 & 1,8 & 1,9 \\
\hline Latvia & 2,4 & 2,4 & 2,5 & 2,4 \\
\hline Poland & 1,8 & 1,9 & 1,9 & 2,2 \\
\hline Romania & 1,5 & 1,3 & 1,2 & 1,1 \\
\hline Slovenia & 2,2 & 2,1 & 2,1 & 2,1 \\
\hline Slovakia & 2,6 & 2,8 & 2,9 & 2,8 \\
\hline Turkey & 3,4 & 1,3 & 1 & 0,8 \\
\hline
\end{tabular}

\section{Infrastructure of knowledge- based economy}

\subsection{Education}

Recent scientific research works show that higher education plays a leading role in the development of the knowledge economy. Hill and Webb state the 
following: "this role is manifested through the creation, refinement and application of knowledge, especially through research and development, in the expanding output of people with higher level knowledge and skills, and in the dissemination of knowledge through innovation networks"(Hill \& Webb (2001)).

The analysis of statistical data provided in Figure 2 (Change of number of students and number of 0-24 age population in 1990-2002) show that the birth rate in Lithuania is diminishing.

For instance, the number of 0 to 24 - year - olds has decreased by $16 \%$ during 1990-2002. However, despite the low birth rate, the general number of pupils and students has been increasing since 1993, and has grown by $22 \%$ in the past 10 years. Notably, that pupils and students made up $23.3 \%$ of all inhabitants in 2002-2003. The tendencies of grow are especially evident at the secondary and higher education levels. For example, the number of students in high schools has increased twofold in five years period. In 2000$200142.3 \%$ of 20 -year-olds and $15.8 \%$ of 24 -yearolds studied at institutions of higher education. These figures were higher than in the EU countries $(30 \%$ and $18 \%$ respectively).

The reason why such large proportions of young people are seeking high education has been caused by business sector raising high requirements for the potential employees. According to Morris \& Western, the growing number of research works suggests that some of the new jobs that have been created over the past two decades are fundamentally different from the ones that have been lost (Morris \& Western, 1999). Therefore, the new jobs that have been created in last decade tend to favour employees with high education over those with less education. The same tendencies in Lithuanian business sector have been caused the higher popularity of high education studies.

Notably, that the fields with highest percentages of students are business and administration, low studies. On the other hand, statistical data provided in Table 3 shows that the number of graduates in mathematics, science and technology has increased. Hence, taking into account the EU's 2010 goals and in order to increase innovation and research capacity, Lithuania should increase the total number of graduates in mathematics, science and technology.

It should be noted that in the knowledge society people must continue to improve and update competencies and skills. However, the issue seems to be even more urgent when the lifelong learning in Lithuania is taken into account. The statistical data provided in Figure 3 (Percentage of population aged 25-64 participating in education and training in 4 weeks) shows that the average EU-15 percentage is $8.5 \%$, meaning that, for any period of a month, 8-9 out of 100 people will have participated in education and training activities. For instance the best performing countries are the UK, Sweden, Finland and Denmark. The average level of these countries is above $20 \%$. However, according this benchmark Lithuania lags behind the best performing countries and performs below the EU-15 level.

\subsection{Research and development}

It is usually accepted to connect the growth of the knowledge economy with R\&D system. It is worth noting that the Lithuanian R\&D infrastructure is dominated by the public sector, which includes such institutions as universities, academies, research institutions, state research institutes, and state research

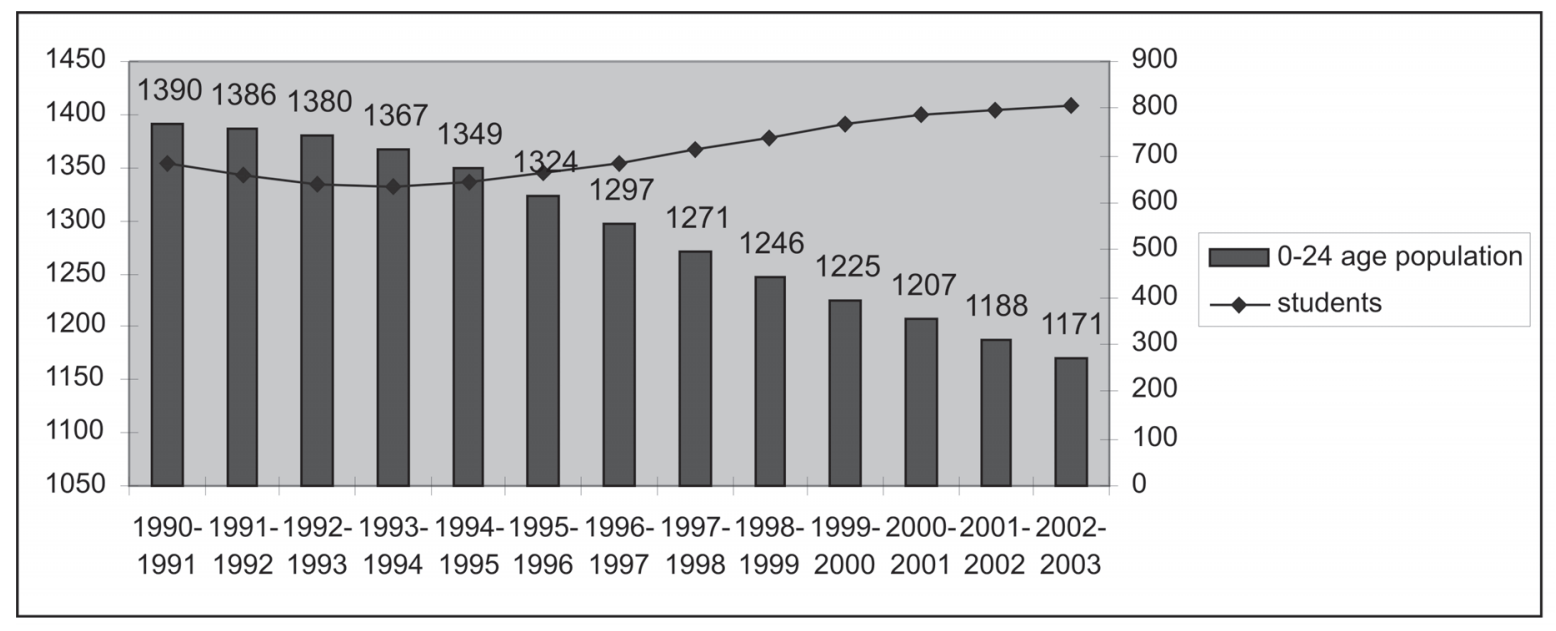

Figure 2. Change of number of students and number of 0-24 age population in 1990-2002 (thousands) (Source: Department of Statistics of Lithuania) 
Table 3. Number of graduates (Source: Eurostat)

\begin{tabular}{|c|c|c|c|c|c|c|c|}
\hline \multirow{2}{*}{ Country } & \multicolumn{3}{|c|}{ Number of graduates (x1000) } & \multicolumn{4}{|c|}{ Number of maths, science and technology graduates (x1000) } \\
\hline & 2000 & 2001 & 2002 & 2000 & 2001 & 2002 & 2003 \\
\hline Latvia & 15.3 & 20.4 & 18.9 & 2.4 & 2.5 & 2.6 & 2.8 \\
\hline Cyprus & 2.8 & 2.9 & $(:)$ & 0.34 & 0.37 & 0.30 & $(:)$ \\
\hline Estonia & 7.1 & 7.6 & 7.8 & 1.3 & 1.4 & 1.3 & 1.7 \\
\hline Hungary & 59.9 & 57.9 & 62.3 & 7.2 & 5.8 & 7.8 & 7.6 \\
\hline Lithuania & 25.2 & 27.5 & 29.8 & 6.6 & 7.0 & 6.9 & 7.7 \\
\hline Poland & $(:)$ & 431.1 & 459.7 & 39.2 & 44.8 & 49.8 & 55.2 \\
\hline Slovenia & 11.5 & 12.0 & 14.3 & 2.6 & 2.4 & 2.8 & 2.6 \\
\hline $\begin{array}{l}\text { Czech } \\
\text { Republic }\end{array}$ & 38.4 & 43.6 & 43.7 & 9.4 & 9.6 & 10.1 & 10.7 \\
\hline Slovakia & 22.7 & 26.2 & 28.2 & 4.7 & 6.7 & 7.1 & 7.7 \\
\hline Romania & 68.0 & 76.2 & 17.1 & 18.4 & 20.4 & 30.6 & 19.7 \\
\hline Bulgaria & 46.7 & 47.5 & 50.6 & 8.1 & 9.1 & 13.4 & 9.6 \\
\hline Croatia & $(:)$ & $(:)$ & $(:)$ & $(:)$ & $(:)$ & $(:)$ & 3.4 \\
\hline Turkey & 190.1 & 241.5 & 233.6 & 57.1 & 61.5 & 65.9 & 69.6 \\
\hline
\end{tabular}

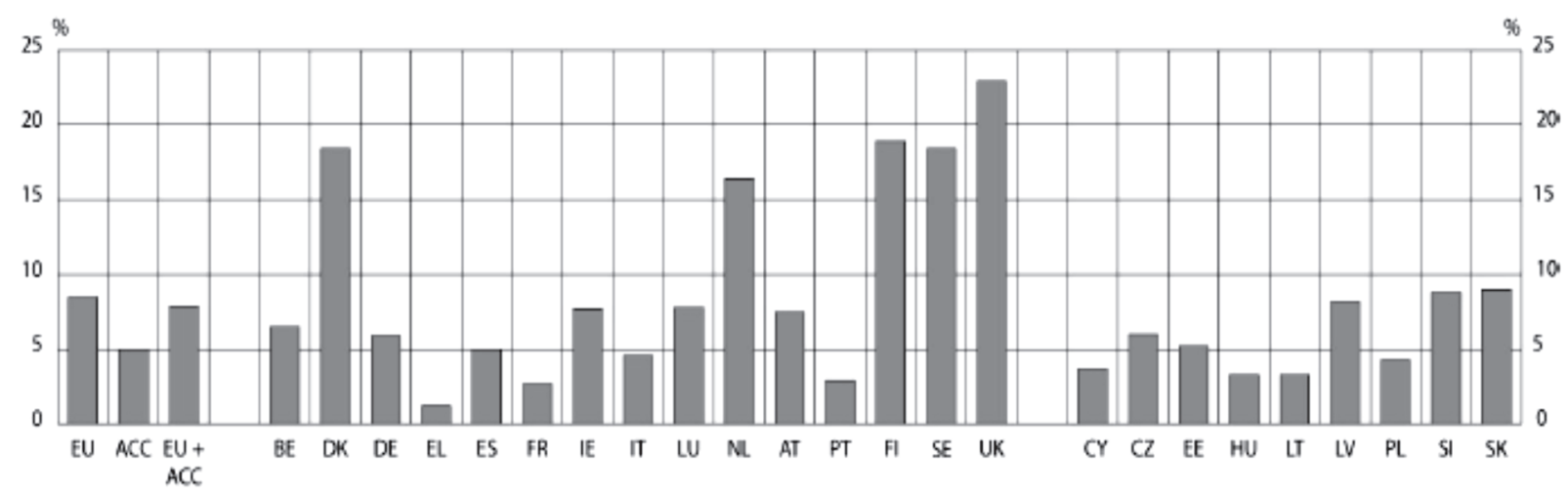

Figure 3. Percentage of population aged 25-64 participating in education and training in 4 weeks (Source: Council of the European Union)

institutions. However, Lithuania's ability to systematically generate, acquire, disseminate, and apply knowledge in new ways with the purpose to solve problems is constrained (World Bank, 2003). Despite the existence of universities, state research institutions, a business community and the institutions aiming to support technology applications, Lithuania has not managed to bring all these institutions into in a coordinated framework allowing linking the R\&D community with business sector.

Examination of recent data provided by Eurostat, allow to conclude that while on average about $50 \%$ of researchers' FTEs in the EU are concentrated in the Business Enterprise Sector (BES), in Estonia, Greece, Latvia, Lithuania, Poland, Portugal and Slovakia this sector's share of researchers is $25 \%$ or less (Statistics in Focus, 2005). The same situation exists in the Candidate Countries such as Bulgaria and Croatia. Except for Bulgaria in all these countries, the bulk of researchers belong to the Higher Education Sector (HES).

Due to the lower Lithuanian investments in the R\&D sector, some problems associated with the development of an internationally competitive science sector occurred. On the other hand the lack of incentives for $R \& D$ activities in the private sector leads to the low innovation performance of the system as a whole - the patenting activities are weak (36 per million inhabitants) compared to EU countries, and according to the indicator on European patents (2.5 per 
million inhabitants) Lithuania stand only higher than Latvia, Romania and Poland (Radosevic, 1999). Innovations occur at enterprise level in Lithuania in laser technology and biotechnology industries. However it has taken place in relatively few and isolated cases. Taking into account the small size of the Lithuanian economy, it can be concluded that the international patenting rate, indicating the vitality of the knowledge economy, should be significantly higher.

Although, Lithuania is leading among the new Member States and is above the EU mean in such innovation indicators as S\&E graduates (rank among EU25 -5), population with tertiary education (rank among EU25 - 12), high share of value added in high tech manufacturing (rank among EU25 - 15), the entire manufacturing sector makes up a very small share of the total economy today (4.4 percent)); innovation co-operation in manufacturing SMEs (rank among EU25 - 4) (European Innovation Scoreboard, 2004). The analysis of statistical data provided in Figure 4 (Innovation performance relative to EU25 Lithuania) allow concluding that Lithuania is lagging behind in important indicators such as patenting, employment in high tech sectors, participation in lifelong learning and early stage and high - tech venture capital.

Notably, that one of the benchmarks of the country's
Table 4. Exports of high technology products as a share of total exports (Source: Eurostat)

\begin{tabular}{|l|r|r|r|}
\hline \multicolumn{1}{|c|}{ Country } & \multicolumn{1}{|c|}{2001} & \multicolumn{1}{c|}{2002} & \multicolumn{1}{c|}{2003} \\
\hline EU -25 & 20.5 & 18.2 & 17.8 \\
\hline Bulgaria & 1.8 & 2.6 & 2.9 \\
\hline Czech Republic & 9.1 & 12.3 & 12.3 \\
\hline Estonia & 17.1 & 9.8 & 9.4 \\
\hline Hungary & 20.4 & 20.3 & 21.7 \\
\hline Lithuania & 2.9 & 2.4 & 3 \\
\hline Latvia & 2.2 & 2.3 & 2.7 \\
\hline Poland & 2.7 & 2.4 & 2.7 \\
\hline Romania & 4.9 & 3.1 & 3.3 \\
\hline Slovenia & 4.8 & 4.9 & 5.8 \\
\hline Slovakia & 3.7 & 2.9 & 3.4 \\
\hline Turkey & 3.2 & 1.6 & 1.8 \\
\hline
\end{tabular}

competitiveness is high tech exports. Statistical data provided in Table 4 refers that Lithuania is lagging behind EU-25 average (Statistics in Focus, 2005).

On the other hand, the number of patents shows growth in intangible knowledge capital and the size of the science and engineering workforce serve as the indicator of growth in human capital. However, according to these benchmarks, Lithuania lags behind

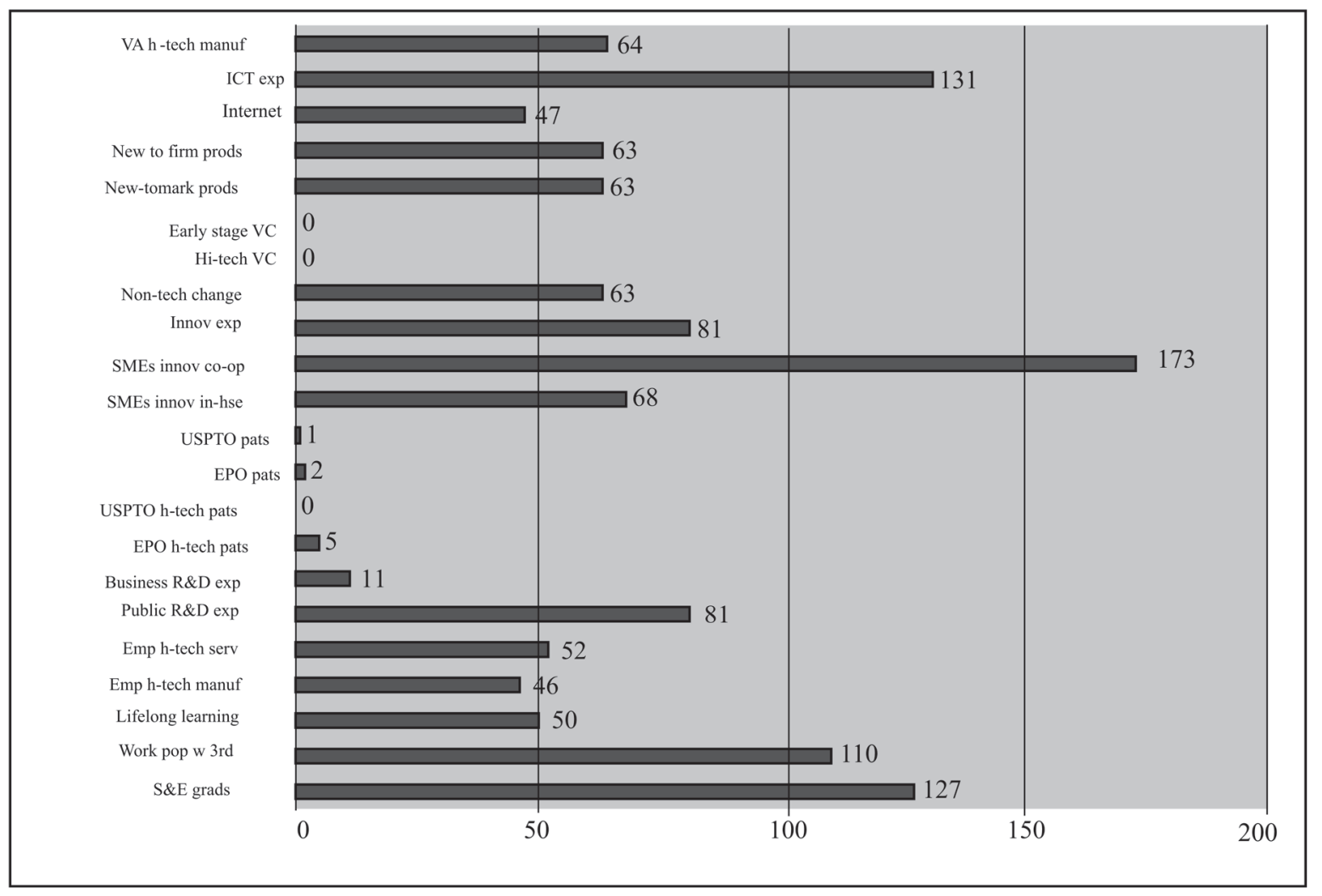

Figure 4. Innovation performance relative to EU25 - Lithuania (Source: European Innovation Scoreboard) 
other EU countries. The current weakness of country is caused by low business $\mathrm{R} \& \mathrm{D}$ expenditure, unsatisfactory R\&D output (in terms of patents) and low number of scientists.

The isolated Lithuanian science system was the main factor that caused the aging of the Lithuanian research population, low levels of funding, brain drain and decision of researchers to change the profession. Furthermore, integration of Lithuania into the EU might deepen this gap, due to lack of career opportunities and working conditions inside the country and new opportunities within the EU.

\section{Informational Infrastructure}

According to Knowledge Economy Index, Lithuania made progress between 1995 and the period (ranging from 2000 to 2002), moving from a score of 56 to 6.7 (Figure 5). It should be noted that the Knowledge Economy index was calculated according to the methodology of World Bank Institute according to the four main dimensions of a knowledge economy: education, innovation, information society (infrastructure), and economic and institutional framework.

Taking into account the four dimensions of a knowledge economy, Lithuania made the most progress in developing its information and communications infrastructure and improving its economic and institutional framework (World Bank, 2003). However, according to the data of the research carried out by the World Economic Forum that assessed the readiness and usage of information and communication technologies in 102 countries,
Lithuanian business uses these technologies less than the population of the country as a whole: according to the indicators of readiness and usage, business is in the 32nd and 50th position out of 102, and the population is in 42nd and 45th position; the capacity of the Government was evaluated at the 38th and 63rd position (World Economic Forum, 2004).

It is important to point out that the growth of the knowledge economy is connected with information technology. Information technology gives greater efficiency in different economic activities. At the same time it provides a great range of possibilities for innovative activities. A 'knowledge friendly' environment means that accents in economic development have to be shifted from the traditional business sectors to the provision of computer servers and telecommunications and the promotion of market institutions conducive to new ideas.

Despite the fact that Lithuania is dominated by lowtech industries, high - tech industries, such as biotechnologies, laser and medical equipment, IT, as well as mid - high tech industries, such as electrical and optical equipment, machinery are performing at an internationally competitive level. Besides that, IT sector was among the fastest growing sectors in Lithuania. The analysis of statistical data provided in Figure 6 (The Development of Lithuania's ITT Sector) shows that since 1994, this sector has grown almost six fold.

The growth in ITT sector was influenced by increased investments in the business market segment and the quickly developing consumer market. For instance, mobile phone penetration increased from $13 \%$ to

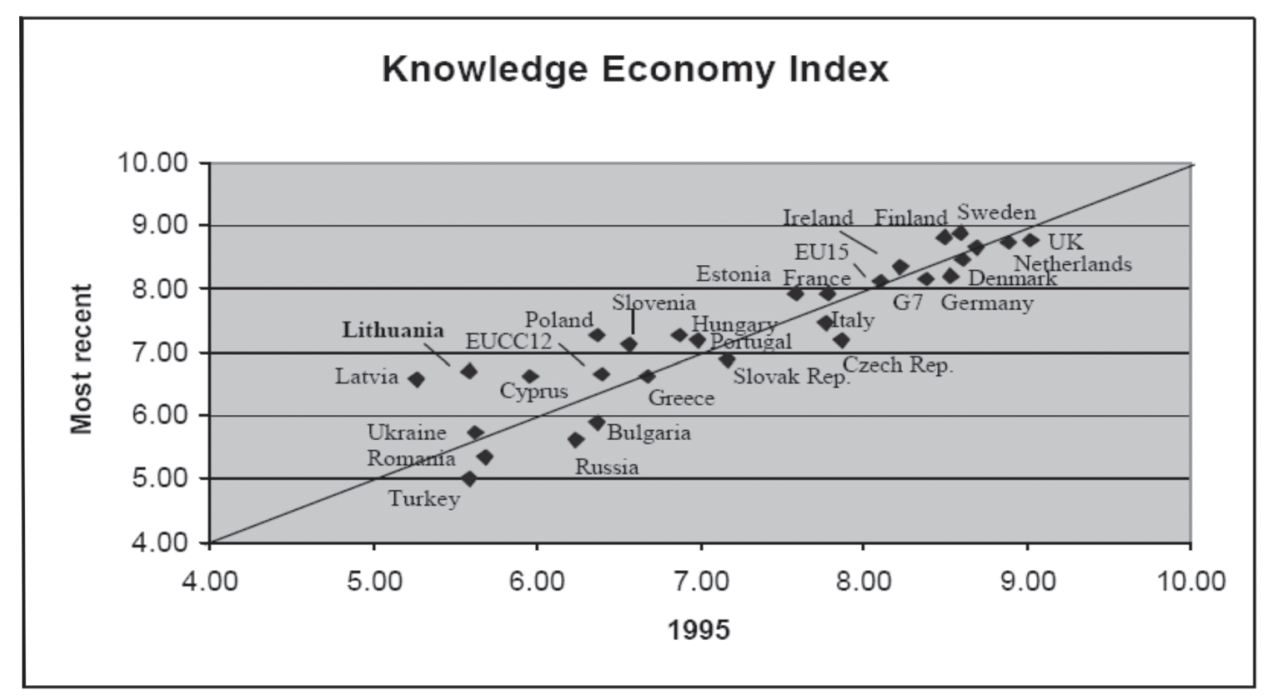

Figure 5. Knowledge economy index: scores for various countries, 1995 and 2000-02 (Source: World Bank Institute) 


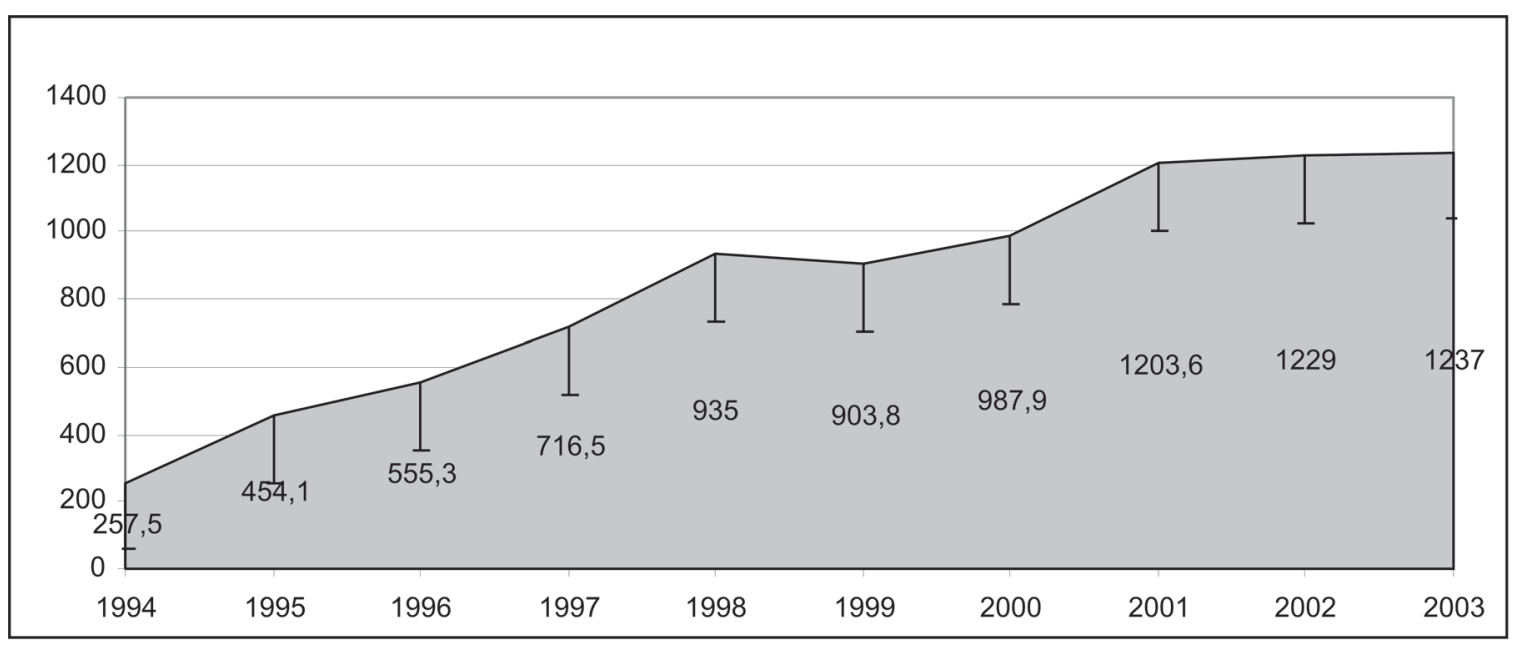

Figure 6. The Development of Lithuania's ITT Sector (mill. EUR) (Source: Infobalt)

$62 \%$. The contribution of advanced technology in the structure of GDP has increased by nearly $17 \%$ over five year period. However, the role of advanced technology-based industries in the economy remained modest and in 2002 accounted for only $1.06 \%$ of GDP.

\section{Conclusions}

This paper has revealed that Lithuania is much behind the EU countries by its knowledge based economy development. The conclusion we can draw is, that economy of post-communist countries is more oriented toward traditional business. Hence, the dominance of low skill industries in Lithuania might serve as the main obstacle seeking the competitive advantage. The role of advanced technology-based industries in the economy remains modest. Besides that, the current expenditure into such areas as $\mathrm{R} \& \mathrm{D}$ and IT development does not fully meet the needs of the rapidly growing knowledge economy. Such factors, as the diminished contribution of research and development to the economy over the five-year period also hinder opportunities for the growth of the country's intellectual potential.

Taking into account these facts, Lithuania should more invest into the education of "competitive personality" fit for the knowledge economy. However both employers and employees pay so little attention to the acquisition of new knowledge. Thus it is one of the main reasons why Lithuania is lagging behind in the implementation of information technology in production and services. The too-low attention to employee training is one of the reasons for the low labour productivity rate.

Thus, the country still has to solve the problems typical of the new participants of the global economy. Not accidentally, economy based on knowledge is becoming one of Lithuania's priorities. In order to eliminate these obstacles Lithuania set up the priorities to use the EU funds for the support of the knowledge economy. Lithuania established priorities regarding the communication and informatics sectors. According these priorities, in the long perspective these sectors will take the dominant position in the structure of the country's economy and efficiently stimulates the development of the remaining branches of Lithuania's economy.

\section{References}

Arrow K.J. The economic implications of learning by doing. Review of Economic Studies, 29, No 80, 1962.

Audretsch David B. \& Thurik, A. Roy Capitalism and democracy in the 21s Century: from the managed to the entrepreneurial economy. Journal of Evolutionary Economics, 10, 2000, p. 17-34.

Barnacle R. A critical ethic in a knowledge economy: research degree candidates in the workplace. Studies in Continuing Education, 23, 3, 2004, p. 355-368.

Council of the European Union, Education \& training 2010: The success of the Lisbon strategy hinges on urgent reforms, Brussels, 3 march, 2004, http:/europa.eu.int/ comm/education/policies/2010/doc/jir_council_final.pdf

European Innovation Scoreboard - Country pages, 2004, http://rendchart.cordis.lu/scoreboards/scoreboard2004/ pdf/eis_2004_annex2.pdf.

European Trend Chart on Innovation. Annual Innovation Policy for Lithuania. European Commission 2003-2004.

Education across Europe 2003. Eurostat Theme 3 Population and Social Conditions, http://www.om.hu/ doc/upload/200507/education_in_europe_2003.pdf.

Hill, S. \& Webb A. A More Prosperous Wales: From a 
National Economic Development Strategy to a Knowledge Economy Action Plan The Bevan Foundation Papers, No1, Tredegar, 2001.

Howells J. Tacit knowledge, innovation and technology transfer. Technology Analysis and Strategic Management, 8(2), 1996, 91-106.

Makarov, V. The Knowledge Economy: Lessons for Russia. Social Sciences, 35 (1), 2004, p. 19-30.

Morris M. \& Western B. Inequality in earnings at the close of the twentieth century. Annual Review of Sociology, 25, 1999, p. 623-680.

Muller, K., \& H. Etzkowitz. S\&T Human Resources: The Comparative Advantage of the Post-Socialist Countries. Science and Public Policy, 27, No 4, 2000, p. 285-376.

Organisation for Economic Co-operation and Development (OECD), Science, Technology and Industry Scoreboard. Towards Knowledge Based Economy. Paris: OECD, 1999.

Organisation for economic Co-operation and Development (OECD) The knowledge based economy, Science, Technology and Industry Outlook, Paris: OECD, 1996.

Porter M. Clusters and the new economics of competition. Harvard Business Review, 76(6), 1998, p. 77-91.

Radosevic, S. Patterns of innovative activities in countries of central and eastern Europe: An analysis based on comparison of innovation surveys, SPRU Electronic working paper No 35, 1999, University of Sussex.

Statistics in Focus. Science and technology. 2/2005, http:// epp.eurostat.cec.eu.int/cache/ITY_OFFPUB/KS-NS-05002/EN/KS-NS-05-002-EN.PDF
Roberts J. The drive to codify: implications for the knowledge-based economy. Prometheus, 19, 2, 2001, p. 99-116.

Rosenberg N. Inside the black box: technology and economics. Cambridge University Press, Cambridge, 1982.

Sporer Z. Knowledge-based economy and social capital in Central and East European countries. Eastern European Economics, 42, 6, 2004, p. 39-71.

Statistics in Focus. Science and Technology. 3/2005, http:/ /epp.eurostat.cec.eu.int/cache/ITY PUBLIC/KS-NS-05003/EN/KS-NS-05-003-EN.PDF.

Statistics in Focus. Science and Technology. 7/2005, http:/ /epp.eurostat.cec.eu.int/cache/ITY_OFFPUB/KS-NS-05007/EN/KS-NS-05-007-EN.PDF.

Statistics in Focus. Science and technology. 8/2005, http:// epp.eurostat.cec.eu.int/cache/ITY_OFFPUB/KS-NS-05008/EN/KS-NS-05-008-EN.PDF.

The World Bank Europe and Central Asia Region. Lithuania Aiming for a Knowledge Economy, March 2003, http:/ /www-wds.worldbank.org/servlet/WDSContentServer/ WDSP/IB/2003/04/25/000094946_03041204014387/ Rendered/PDF/multi0page.pdf.

World Economic Forum. The Global Information Technology Report 2003-2004, Oxford University Press, $2004, \mathrm{http}: / / \mathrm{ww}$ w. infodev.org/files/ 839_file_GITR2003.pdf 